\title{
BMJ Open Medical management of acute upper respiratory infections in an urban primary care out-of-hours facility: cross- sectional study of patient presentations and expectations
}

\author{
Raymond O'Connor, ${ }^{1}$ Jane O'Doherty, ${ }^{1}$ Andrew O'Regan, ${ }^{1}$ Aoife O'Neill, ${ }^{2}$ \\ Claire McMahon, ${ }^{3}$ Colum P Dunne ${ }^{1}$
}

To cite: $0^{\prime}$ Connor $\mathrm{R}$,

0'Doherty J, 0'Regan A, et al. Medical management of acute upper respiratory infections in an urban primary care out-ofhours facility: cross-sectional study of patient presentations and expectations. BMJ Open 2019;9:e025396. doi:10.1136/ bmjopen-2018-025396

- Prepublication history and additional material for this paper are available online. To view these files, please visit the journal online (http://dx.doi. org/10.1136/bmjopen-2018025396).

Received 13 July 2018 Revised 12 December 2018 Accepted 2 January 2019

Check for updates

(C) Author(s) (or their employer(s)) 2019. Re-use permitted under CC BY-NC. No commercial re-use. See rights and permissions. Published by BMJ.

${ }^{1}$ Graduate Entry Medical School, University of Limerick Faculty of Education and Health Sciences, Limerick, Ireland

${ }^{2}$ Department of Mathematics and Statistics, University of Limerick, Limerick, Ireland ${ }^{3}$ Clinical Quality and Administration Department, Shannondoc Out of Hours General Practitioner Service, Limerick, Ireland

Correspondence to Dr Raymond 0'Connor; Raymond.0Connor@ul.ie

\section{ABSTRACT}

Objectives The purpose of this study was to examine the expectations of patients attending an urban primary care out-of-hours $(\mathrm{OOH})$ facility with acute upper respiratory tract infection (acute URTI) regarding clinical examination, symptom management, information on their condition, reassurance, antibiotic treatment and other possible options including referral.

Design Cross-sectional design.

Setting One urban primary care $\mathrm{OOH}$ facility located in the midwest of Ireland.

Participants 457 patients filled out a questionnaire while waiting in the $00 \mathrm{H}$ facility; 22 surveys were excluded as the patients did not present with symptoms of acute URTI resulting in 435 patients' data being included in this study. There were $59.5 \%$ female participants and $40.5 \%$ male participants.

Results 435 patients with acute URTI symptoms participated in the survey, representing $25.4 \%$ of those attending the single branch where the survey was conducted $(n=1715)$. Of the study participants, $43 \%$ were aged under 6 years and $60 \%$ were women. The most common presenting symptoms were cough $(72 \%)$, throat ache $(46 \%)$ and common cold $(26 \%)$. The most common expectations were for further examination (53\%), reassurance (51\%), information (49\%) and medication for cough (47\%), with $34 \%$ expecting an antibiotic.

Conclusions Only one in three patients attending this primary care $\mathrm{OOH}$ facility with acute URTI symptoms had an expectation of antibiotics, with most seeking further assessment, information and reassurance. Recognition of such expectations may be important considerations for clinicians when deciding on management options for patients with acute URTI.

\section{BACKGROUND}

Antimicrobial resistance (AMR) is a growing threat to global public health. ${ }^{1}$ Increasing consumption of antibiotics is associated with the development of antibiotic resistance at individual, community, national and international levels. ${ }^{2-5}$ It is estimated that 25000
Strengths and limitations of this study

- The study used a previously validated questionnaire that was adapted and piloted by a multidisciplinary research and clinical team.

- The research was conducted over four consecutive months which would mitigate the effects of any public health campaigns aimed at reducing antibiotic use at the time.

- As this is a single-centre study, the population studied in this particular out of hours $\mathrm{OOH}$ service may not reflect those seen in $\mathrm{OOH}$ services throughout Ireland and/or the UK.

- The patient's desire for antibiotics was not assessed against the clinician-assessed need for antibiotics. Severity and duration of the illness was not assessed which may have affected patient expectation for antibiotics.

people in the European Union die annually as a result of infections caused by resistant bacteria, at a societal cost of approximately $€ 1.5$ billion annually. ${ }^{6}$ Over the last 30 years, no major new types of antibiotics have been developed. ${ }^{7}$ Therefore, antibiotic stewardship programmes, aiming to ensure the judicious use of antimicrobials by preventing their unnecessary use, have been established. ${ }^{18-12}$

Acute upper respiratory tract infection (acute URTI), which incorporates the term 'upper respiratory infection', includes infections such as otitis media, pharyngitis, sinusitis and acute bronchitis. ${ }^{13}$ It is the most common reason for antibiotic prescription in adults ${ }^{13}$ and children. ${ }^{14}$ These prescriptions are often inappropriate in that they may be unnecessary, lead to increased antibiotic resistance and put patients at risk of adverse events. ${ }^{13}$ Typically, inappropriate antibiotic prescribing occurs when a doctor prescribes 
an antibiotic that is not clinically indicated. The benefits of antibiotics are marginal for the management of most cases of acute URTI, ${ }^{15-22}$ including sore throat. ${ }^{23}{ }^{24}$ Internationally, research shows that, with few exceptions, ${ }^{25}$ inappropriate prescribing of antibiotics for patients with mainly acute URTI is common. ${ }^{26-30}$ This is thought to be related to a poor standard of knowledge among the general public regarding the usefulness of antibiotics in acute URTI, with widespread belief that antibiotics work well for treating viral infections. ${ }^{31} 32$

It has been reported that $75 \%$ of overall antibiotic prescribing takes place in primary care.$^{33}$ For example, the majority of outpatient antibiotic prescriptions in the USA are for acute URTIs. ${ }^{134}$ In Ireland, the UK and many other countries, out-of-hours $(\mathrm{OOH})$ services are an integral part of primary care provision, providing primary care outside of 'core' contracted hours during weekday evenings and nights and on weekends or bank holidays. This care is usually for clinical cases that are deemed to be of sufficiently urgent nature that they cannot wait until the next available routine consulting period. Internationally, acute URTIs are estimated to constitute $9 \%$ of the consultations in general practice, while the corresponding proportion in the $\mathrm{OOH}$ service is $16.7 \% .{ }^{35}$ Hence, this service handles a substantial proportion of acute URTIs and is, thereby, potentially an important contributor to overall antibiotic consumption.

Patterns of antibiotic prescribing that clearly do not adhere to guidelines have been reported. ${ }^{36}{ }^{37}$ In some regions, this has contributed to a $25 \%$ rate of antibiotic prescribing for children with fever in an $\mathrm{OOH}$ setting. ${ }^{38}$ Giesen described how national clinical guidelines are not suited to the context of the $\mathrm{OOH}$ setting leading to clinical uncertainty for doctors. ${ }^{39}$ This has resulted in quality of antibiotic prescribing being less than optimal. ${ }^{40}$ Trends in prescribing have also suggested that there may be a partial displacement of antibiotic prescribing from in-hours to the $\mathrm{OOH}$ setting, where patients with acute infective symptoms seeking antibiotics present to the $\mathrm{OOH}$ service after refusal by the in-hours general practice. ${ }^{41}$ In contrast, other studies have shown antibiotic prescription rates to be similar in the $\mathrm{OOH}$ setting compared with the daytime in-hours setting. ${ }^{35} 42$

While it is true that poor public understanding of the usefulness of antibiotics in acute URTI may increase patient expectation for antibiotic prescription, there is evidence that clinical examination and explanation of the diagnosis is important to patients' satisfaction with the consultation. ${ }^{43}$ It has also been shown that taking a patient's concerns seriously, conducting a physical examination, communicating a treatment plan and explaining treatment decisions all increase patient satisfaction with the management of acute URTI. ${ }^{44}$

One of the most important factors influencing doctors prescribing of antibiotics for acute URTI is patient expectation. ${ }^{45-59}$ However, doctors often overestimate the level of this expectation. ${ }^{5460-63}$
Hence, there is an important need to determine what patients presenting to an OOH centre with acute URTI symptoms are expecting from their consultation with the healthcare professional (HCP). The purpose of this study was to examine patients' expectations of clinical examination, symptom management, information on their condition, reassurance, antibiotic treatment and other possible options including referral. This insight into patient expectation will inform HCPs dealing with patients presenting with acute URTI in an $\mathrm{OOH}$ setting.

\section{METHODS}

\section{Study setting}

The 'Shannondoc' primary care $\mathrm{OOH}$ facility (hereinafter referred to as 'the $\mathrm{OOH}$ facility') in Limerick City, in the midwest of Ireland is the regional primary care setting for treating patients between 18:00 and 08:00 hours on weekdays and at all hours over weekends. The $\mathrm{OOH}$ facility has 12 branches throughout the region. It has a mixed private-public system with $45 \%$ of the population eligible for free care under a means-tested General Medical Services card or doctor visit-only card which is issued by the Irish Health Service Executive ${ }^{64}$ Eligibility criteria for free medical care include: age under 6 or over 70 years or earning below a certain figure based on family size. This group is hereinafter referred to as those eligible for free care. General practitioners (GP) (who are self-employed) are paid a 'per capita' fee by the state for their care. These patients do not pay directly for GP consultations whereas patients without a card pay an average of $€ 55$ per consultation.

\section{Participants}

Each day reception staff distributed the paper-based questionnaires along with information and consent forms to patients in the waiting room, prior to their consultation. The trained reception staff are experienced at working in a supervised clinical setting $\mathrm{OOH}$. Only patients attending with symptoms of acute URTI were invited to participate in the study. For those aged under 18 years, parents or guardians were asked to complete the questionnaire. Reception staff were briefed by a member of the research team (ROC) on the aims of the study and given a list of acute URTI symptoms. All questionnaires were completed at the $\mathrm{OOH}$ facility. Completed forms were securely stored in the University of Limerick Graduate Entry Medical School building.

\section{Sample size}

It was calculated that a random sample of 400 patients would be required to estimate the percentage of patients expecting a prescription for antibiotics with $95 \%$ confidence and a margin of error of $5 \%$. While our sample is not randomly selected, this sample size calculation was used to guide recruitment.

\section{Measures}

The questionnaire used was adapted from an instrument used by a recent study of patient experiences of antibiotic 
prescribing by non-medical practitioners. ${ }^{44}$ The modifications made to the original instrument were: eliminating the postconsultation element which asked patients what treatment they were given and ranking their satisfaction with various aspects of the consultation. All patients provided information regarding their age, gender, eligibility for free care and whether this was their first consultation with their $\mathrm{GP}$ or the $\mathrm{OOH}$ facility for the current complaint.

Other data collected included:

- Expecting antibiotics: Yes, no, unsure

- Reasons for seeing the GP: Earache or ear discharge, complaints of nose/sinuses, common cold, throat ache, cough, other reasons, for example, influenza-like symptoms

- What did they expect to receive from the GP: Further examination, information, reassurance, medication for pain relief, nose drops, medication for cough, referral to hospital or specialist, other

The modified questionnaire was piloted among non-medical staff and students in the medical school who were not associated with the study to ensure face validity (see online supplementary appendix 1). Completed questionnaires were deidentified for storage where patients had entered identifying data on the questionnaire during its completion.

\section{Data analysis}

Descriptive statistics were used to explore the demographic profile, patient symptoms and patient expectations. Variables were summarised using graphical and numeric descriptive statistics. Categorical variables were described using counts and percentages. The demographic characteristics of the sample and known characteristics of the population attending the $\mathrm{OOH}$ facility with acute URTI symptoms were compared. The percentage of the sample with an expectation of antibiotics was calculated with a $95 \%$ CI. The difference and corresponding 95\% CI for the difference between two independent proportions (expectation of antibiotics by gender, age group, eligibility for free care and first consultation) were calculated. The $\mathrm{Z}$ test for independent proportions was used to investigate differences between proportions. SPSS V.24 and R software were used for the statistical analysis. Ethical approval for the study was granted.

\section{Patient and public involvement}

Patients were not involved in the design of the study. Patient data were collected but no identifying data were included in this study. Patients were recruited by staff at the $\mathrm{OOH}$ service based on their physical symptoms of acute URTI. Patients will be able to view the results of this study when it is published in a peer-reviewed journal.

\section{RESULTS}

\section{Patient characteristics}

A total of 457 questionnaires were collected during the time period of the study. When reviewing the data, 22 questionnaires were excluded as patients presented
Table 1 Patient characteristics and preconsultation expectations of antibiotics $(n=435)$

\begin{tabular}{ll}
\hline $\begin{array}{l}\text { Patient characteristics and } \\
\text { preconsultation antibiotic expectations }\end{array}$ & $\mathbf{n}(\%)$ \\
\hline $\begin{array}{l}\text { Gender } \\
\text { Male }\end{array}$ & $176(40.5)$ \\
\hline Female & $259(59.5)$ \\
\hline Age (years) & \\
\hline Under 6 & $186(42.8)$ \\
\hline $6-25$ & $130(29.9)$ \\
\hline $25-55$ & $96(22.1)$ \\
\hline $56+$ & $23(5.3)$ \\
\hline Eligibility for free care & \\
\hline Yes & $244(56.1)$ \\
\hline No & $191(43.9)$ \\
\hline
\end{tabular}

First medical consultation for this complaint

\begin{tabular}{lr} 
Yes & $214(49.2)$ \\
\hline No & $221(50.8)$ \\
\hline Expecting antibiotics preconsultation & \\
\hline Yes & $149(34.3)$ \\
No & $45(10.3)$ \\
\hline Unsure & $241(55.4)$ \\
\hline
\end{tabular}

with non-acute URTI symptoms. This yielded a total of 435 questionnaires related to patients with symptoms of acute URTI. This sample represents one in four of the 1715 patients with acute URTI who attended this treatment centre from October 2017 to February 2018 and $3.8 \%$ of the 11455 face-to-face consultations for acute URTI at all treatment centres of the $\mathrm{OOH}$ service in the region during the same period. Patient characteristics and preconsultation expectation for antibiotic treatment are summarised in table 1 .

The majority of the sample were women $(60 \%)$ and over half $(56 \%)$ were eligible for free care. The most common age group was under 6 years of age $(43 \%)$. Two hundred and twenty-one respondents $(50.8 \%)$ indicated that this was not their first consultation for this illness. The demographic characteristics of the sample and known characteristics of the population attending the $\mathrm{OOH}$ facility with acute URTI symptoms are presented in online supplementary material (tables A, B and C)). Compared with the demographic characteristics of the population attending the OOH facility with acute URTI, patients who were eligible for free care were under-represented in the sample (56\% vs $74 \%$ ). The age and gender profile of our sample compared with the $\mathrm{OOH}$ facility were similar (see online supplementary material; tables A, B and C). Older people (over the age of 56 years) are poorly represented in our sample, making up only $5.3 \%$ of the population studied. 
Table 2 Patient expectations for each symptom

Patient expectation

\begin{tabular}{|c|c|c|c|c|c|c|c|}
\hline \multirow[b]{2}{*}{ Symptom* } & \multicolumn{7}{|c|}{ Patient expectation } \\
\hline & $\begin{array}{l}\text { Further } \\
\text { examination }\end{array}$ & Information & Reassure & Pain relief & Nose drops & $\begin{array}{l}\text { Cough } \\
\text { medicine }\end{array}$ & Referral \\
\hline $\begin{array}{l}\text { Earache } \\
(n=64,14.7 \%)\end{array}$ & 39 (60.9) & $34(53.1)$ & 30 (46.9) & $43(67.2)$ & $6(9.4)$ & 23 (35.9) & $0(0.0)$ \\
\hline $\begin{array}{l}\text { Sinuses } \\
(n=105,24.1 \%)\end{array}$ & $53(50.5)$ & $56(53.3)$ & $53(50.5)$ & $47(44.8)$ & 14 (13.3) & $63(60.0)$ & $5(4.8)$ \\
\hline $\begin{array}{l}\text { Common cold } \\
(\mathrm{n}=114,26.2 \%)\end{array}$ & $64(56.1)$ & $54(47.4)$ & $62(54.4)$ & $53(46.5)$ & $10(8.8)$ & $64(56.1)$ & $5(4.4)$ \\
\hline $\begin{array}{l}\text { Throat Ache } \\
(n=202,46.4 \%)\end{array}$ & 104 (51.5) & $99(49.0)$ & $96(47.5)$ & 115 (56.9) & $13(6.4)$ & $101(50.0)$ & $8(4.0)$ \\
\hline $\begin{array}{l}\text { Cough } \\
(\mathrm{n}=314,72.2 \%)\end{array}$ & $164(52.2)$ & 159 (50.6) & 161 (51.3) & $109(34.7)$ & $19(6.1)$ & 195 (62.1) & $12(3.8)$ \\
\hline $\begin{array}{l}\text { Other } \\
(\mathrm{n}=169,38.9 \%)\end{array}$ & $104(61.5)$ & 99 (58.6) & $119(70.4)$ & $59(34.9)$ & $9(5.3)$ & 64 (37.9) & $8(4.7)$ \\
\hline Overall expectation & 528 & 501 & 521 & 426 & 71 & 510 & 38 \\
\hline
\end{tabular}

Counts (\%) presented.

${ }^{*}$ Represents those who presented with symptom (yes response).

†As many patients presented with multiple symptoms, the count exceeds the number of patients surveyed.

\section{Presenting symptoms}

Patients presented with varying symptoms; many of them reported multiple symptoms. Cough was the most common $(72 \%)$, followed by throat ache $(46 \%)$. The least common symptoms included earache or discharge $(15 \%)$ and complaints of nose/sinuses (24.1\%). These symptoms are displayed in table 2.

\section{Patient expectations}

Patient expectations for each symptom are illustrated in figure 1 and described in table 2. Table 2 also gives the overall expectation for each potential response of the HCP. The most commonly expressed expectations were for further examination (53\%), reassurance $(51 \%)$, information (49\%) and medication for cough (47\%). Patients least expected to receive nose drops $(5 \%)$ or a referral to hospital or specialist (3\%). Thirty-four per cent $(95 \% \mathrm{CI}$ $30 \%$ to $39 \%$ ) of patients expected to receive an antibiotic, $10 \%(95 \%$ CI $8 \%$ to $14 \%)$ did not expect to receive an

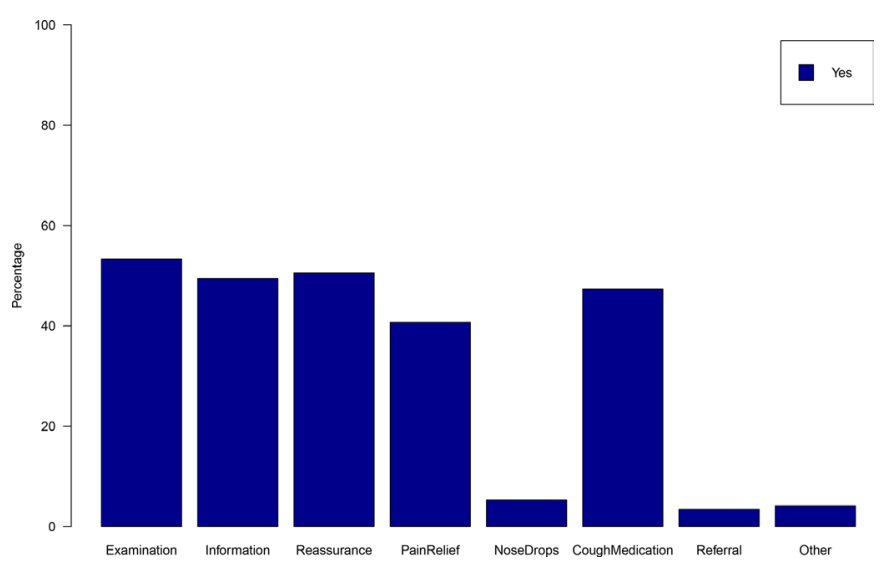

Figure 1 Patient overall expectations. antibiotic and the majority (55\%, 95\% CI $50 \%$ to $60 \%$ ) were unsure whether they would need an antibiotic or not (table 1).

We explored all the differences between expectation of antibiotics by age group, gender, eligibility for free care and whether or not this was the patient's first consultation for this illness. The results are presented in online supplementary table D.

Men were more likely to not expect antibiotics (16\%) compared with $7 \%$ of women (difference $9 \%, 95 \%$ CI for the difference $3 \%$ to $16 \%, \mathrm{p}=0.002$ ). While those eligible for free care were more likely to expect antibiotics $(38 \%)$ compared with those who were not eligible $(30 \%)$, the difference was not statistically significant (difference $4 \%$, $95 \%$ CI for the difference $-1 \%$ to $17 \%, \mathrm{p}=0.09$ ). Patients receiving a subsequent consultation were more likely to expect an antibiotic (37\%) compared with $31 \%$ receiving their first consultation; however, this difference was not statistically significant (difference 6\%, 95\% CI for the difference $-3 \%$ to $15 \%, \mathrm{p}=0.20)$. No significant patterns were observed in the expectation of antibiotics by age group (see online supplementary table $\mathrm{D}$ ).

\section{Differences between patient expectation, expecting an antibiotic and symptom presented}

Patient expectations for each symptom are described in table 2. For each symptom presented, patient expectations of further examination, information or reassurance were similar, with approximately half those who presented with each symptom reporting an expectation to receive these treatments. A large proportion of patients presenting with symptoms of an earache $(67 \%)$ or cough $(65 \%)$ reported expecting to receive pain relief. A large proportion of patients presenting with sinusitis $(60 \%)$ or 
Table 3 Antibiotic expectations of those presenting with different symptoms

Patients expecting an antibiotic

\begin{tabular}{|c|c|c|c|}
\hline \multirow[b]{2}{*}{ Symptoms* } & \\
\hline & $\begin{array}{l}\text { Yes } \\
(n=149,34.3 \%)\end{array}$ & $\begin{array}{l}\text { No } \\
(n=45,10.3 \%)\end{array}$ & $\begin{array}{l}\text { Unsure } \\
(n=241,55.4 \%)\end{array}$ \\
\hline Earache or discharge: 64 (15\%) & $28(43.8)$ & $6(9.4)$ & $30(46.9)$ \\
\hline Common cold: 114 (26\%) & $43(37.7)$ & $8(7.0)$ & $63(55.3)$ \\
\hline Throat ache: 202 (46\%) & $79(39.1)$ & $12(5.9)$ & $111(55.0)$ \\
\hline
\end{tabular}

Count (\%) presented.

${ }^{*}$ Represents those who presented with symptom (yes response).

cough $(62 \%)$ symptoms reported expecting to receive cough medication.

Table 3 presents differences in antibiotic expectations. Patients presenting with symptoms of an earache $(44 \%)$ or throat ache $(39 \%)$ were most likely to expect antibiotics. The majority of patients across all symptoms where 'unsure' whether they would require antibiotics.

\section{DISCUSSION}

Our finding that $34 \%$ of those attending an OOH centre with acute URTI symptoms expected to be prescribed antibiotics prior to seeing the doctor is clinically relevant. The international literature over the last 20 years indicates that patient expectation for antibiotics for management of acute URTI varies from $10 \%$ (47) to $74 \% .{ }^{65}$ In our study, patient expectation for antibiotic treatment ranks third lowest in this literature and second lowest among studies published in the last 10 years. In a qualitative study, Dempsey et al reported a recent decrease in demand for antibiotics for acute bronchitis ${ }^{58}$; however, continued significant demand for antibiotics for acute URTI is evident. This is illustrated in online supplementary Table E.

The statistically significant difference in expecting an antibiotic for gender and age whereby men were less likely to expect an antibiotic than women and older people (56+) are more likely to be 'unsure' whether they will need antibiotics or not $(70 \%)$ may be helpful to the HCP in communicating with the patient regarding the risk-benefit balance of antibiotic treatment for acute URTI. Also, the finding of no difference between those who are entitled to free care (medical card holders) and those who are not, in their expectations of receiving antibiotics, indicates that economic factors (whether or not the patient is paying for the consultation) are not of major importance in antibiotic expectation.

GPs and other primary care doctors are more likely to prescribe antibiotics to patients who expect them or whom they believe expect them. ${ }^{45-59}$ It has been suggested that 'patient expectations' is an all-encompassing phrase that includes other reasons such as limited time, poor doctor-patient communication and diagnostic uncertainty. ${ }^{45}$ Therefore, knowing that only $34 \%$ of patients attending an $\mathrm{OOH}$ service expect an antibiotic for their acute URTI symptoms and that this expectation is not associated with eligibility for free care helps in the clinical decision-making process and allows doctors to concentrate more on the medical need.

Doctors may overestimate the pressure to prescribe antibiotics for acute cough ${ }^{60-62}$ or other acute respiratory illnesses, ${ }^{54}$ often prescribing antibiotics for patients who did not request them. ${ }^{63}$ Wong et al studying a Chinese primary care population presenting with acute URTI symptoms found that concern about illness severity and obtaining a prescription for symptomatic medications, rather than obtaining a prescription for antibiotics, were the main reasons for patients consulting. ${ }^{47}$ Ong et al found, in a study of patients attending an emergency department with acute URTI symptoms, that doctors were only able to identify one in four of those patients who expected antibiotic treatment for their symptoms. ${ }^{54}$ The same study also found that patient satisfaction was not related to receipt of antibiotics but was related to the belief they had a better understanding of their illness. ${ }^{54}$

There is some evidence that patients are less satisfied in general practices that have frugal antibiotic prescribing practices in general. ${ }^{66}$ However, this retrospective study from England with a $36 \%$ response rate did not estimate the effect of communication skills. It could be argued that with enhanced communication skills and with the HCP eliciting and addressing the patients concerns, the satisfaction rating for frugal prescribers would be considerably higher.

Several studies have shown that private patients who pay for their consultations, ${ }^{476768}$ as well as those of lower socioeconomic status, ${ }^{51}$ 69-72 are more likely to be prescribed antibiotics for acute URTI. Our study showed no association between a patient's eligibility for free care (or paying for their consultation) and expectation of an antibiotic for their acute URTI. Because this eligibility was either due to age (under 6 and over 70 years of age) or income, it is difficult to draw direct conclusions. However, 
most importantly and in contrast to earlier studies, ${ }^{4767} 68$ patient expectation for antibiotics was found to be unrelated to having access to free care.

In a study of non-medical practitioners (NMPs), Courtenay et al found reduced levels of satisfaction among patients who expected but did not receive an antibiotic. ${ }^{44}$ This figure indicates that although NMPs appear to have strategies for managing acute URTI consultations, there is still scope for improvement and these prescribers are therefore an important group to involve in antimicrobial stewardship. ${ }^{44}$ Antimicrobial stewardship programmes should continue to expand in the outpatient setting and should emphasise the importance of clear and direct communication between patients and physicians. ${ }^{59} 73$ Patients from our study anticipated further examination, information and symptomatic treatment. These findings closely echo those of recent studies. ${ }^{44754}$ It is important to continue with public health campaigns to educate the public on the ineffectiveness of antibiotics in treatment of acute URTI, which has been shown to reduce public expectation for antibiotics in such cases. ${ }^{74}$

Our sample represented $25 \%$ of the 1715 patients with acute URTI who attended the single branch of the $\mathrm{OOH}$ facility from October 2017 to February 2018 where all the sampling was conducted. All patients had acute URTI symptoms. Although older people are under-represented, the overall gender profile of those attending at the $\mathrm{OOH}$ facility with acute URTI symptoms is broadly similar to those investigated in this study (see online tables A and $\mathrm{B}$ in supplementary material), suggesting that our results are representative of those attending at the $\mathrm{OOH}$ facility during the study period. However, the proportion of those surveyed who were eligible for free care differed considerably from the overall proportion of those attending at the $\mathrm{OOH}$ facility with acute URTI during the study period (56\% compared with $74 \%$ ). It can also be argued that people who decide that their illness is severe enough that they need to see a locum GP in an $\mathrm{OOH}$ service in the weekend, evening or late at night and pay at least $€ 55$ as a fee for doing so have a much greater motivation for getting an antibiotic prescription. Any other medication that they receive from the GP (eg, analgesia, cough bottles and antipyretics) does not require a prescription. The fact that $2 / 3$ of respondents were unsure of whether they expected to receive an antibiotic or did not expect to receive one is indicative that the message on AMR and the overuse of antibiotics has reached the mindset of those attending an $\mathrm{OOH}$ centre.

It is difficult to explain why over $50 \%$ of respondents had previously consulted for this particular complaint. We did not ask when this previous consultation had taken place. Repeat consultation rates of between $15 \%$ and $20 \%$ in children with acute URTI and between $20 \%$ and $30 \%$ in adults with lower respiratory tract infections (LRTIs) have been described. ${ }^{75}$ Between a half and two-thirds of adults with LRTI who reconsult are prescribed antibiotics, despite little evidence of an infection requiring antibiotics. ${ }^{75}$ However, an important finding from this study was that no association was identified between whether this was the patient's first or subsequent consultation for the presenting illness and their expectation of being prescribed an antibiotic.

This study contains several strengths. We used a previously validated questionnaire that was adapted and piloted by a multidisciplinary research and clinical team. The research was conducted over four consecutive months which would mitigate the effects of any public health campaigns aimed at reducing antibiotic use at the time. Patients or guardians filling in the short and anonymous questionnaire before the consultation in the waiting room meant that respondents were more likely to be honest in their opinion. The gender profile of our sample is broadly similar to that of the population attending during the study period with acute URTI symptoms, although older people are under-represented. Reception staff received training from the research team and were tasked with identifying and recruiting participants, ensuring that only those with acute URTI symptoms were surveyed. The higher number of private patient respondents helped to ensure that the finding that they do not expect antibiotics is reliable. Previous studies of this subgroup have indicated that they have a higher expectation for antibiotics for acute URTI.

There are also some limitations. Our study surveyed people attending only one urban $\mathrm{OOH}$ service. It is possible that those who refused to participate in the survey were more severely ill than those who did and were more likely to look for antibiotics (approximately $5 \%$ of those requested, refused to participate). The demographics of those who refused to participate were not studied. As this is a single-centre study, the population studied in this particular $\mathrm{OOH}$ service may not reflect those seen in OOH services throughout Ireland and/or the UK.

Another limitation is that ours was not a randomly selected sample. The non-probability nature of our sample means that bias may have been introduced and some groups under-represented.

While every effort was made to ensure that this was a representative sample of those attending with acute URTI, it is possible that the results were skewed as those eligible for free care was slightly lower than the centres overall population. Older people (over the age of 56 years) are poorly represented in our sample. It is possible that the results would have been different if older people were better represented. Reception staff who were not medically trained were charged with the tasks of distributing questionnaires. This is a potential limitation in that they may have not correctly identified (and therefore missed) a cohort of patients who had acute respiratory tract infections. However, the note of the patient's initial presenting symptom to the call centre was available to the reception staff which would have minimised this. The patient's desire for antibiotics was not assessed against the clinician-assessed need for antibiotics. However, the point of the study was to assess overall patient expectation. Severity and duration of the illness was not 
assessed which may have affected patient expectation for antibiotics.

\section{CONCLUSIONS}

A large proportion of those attending OOH GP service do not have fixed ideas regarding antibiotics and are seeking further assessment, information and reassurance. Most seem to be amenable to not receiving an antibiotic for their illness if their underlying needs are met. This group includes patients eligible for free care as well as those paying for their consultation. Communication and clinical skills of healthcare professionals need to be optimised to ensure reduction in antibiotic prescribing.

\section{Recommendations for further research}

The high number of repeat attendances for acute URTI requires further study. A qualitative study of patients attending $\mathrm{OOH}$ setting to elicit what their intentions are for attending and their understanding of AMR is also appropriate.

Acknowledgements Professor Ailish Hannigan, Professor of Biostatistics University of Limerick Graduate Entry Medical School, for help with study design and analysis. Professor Molly Courtenay, School of Healthcare Sciences, Cardiff University, Cardiff, UK for permission to adapt their patient questionnaire. Mike Finucane and Deirdre Walsh, 'Shannondoc' head office, Shelbourne Rd., Limerick City. Noeleen Lyons, Maura O'Regan, Paul Gallagher from 'Shannondoc' Dooradoyle Treatment Centre, Limerick City.

Contributors ROC conceived the study. AOR, JOD, CMM and ROC were involved in the design of the study. ROC and CMM collected the data. JOD and ROC inputted the data. AON carried out statistical analysis. ROC, CD, AOR and JOD wrote the first draft of the paper. All authors made critical comments on all drafts of the paper, as well as read and approved the final manuscript.

Funding This research was part funded by the Irish College of General Practitioners Research and Education Foundation.

\section{Competing interests None declared.}

Patient consent for publication Not required.

Ethics approval Ethical approval for the study was granted by the Health Service Executive Mid-West Research Ethics Committee. Ethics approval number: 068/17.

Provenance and peer review Not commissioned; externally peer reviewed.

Data sharing statement Deidentified participant data are available upon request from the principal author Dr Raymond 0'Connor for a 6-month time period from publication. Reuse is permitted with the consent of all of the authors. The data sets generated and/or analysed during the current study are not publicly available due to variables that could identify GPs or patients through name of practice and location but are available from the corresponding author on reasonable request.

Open access This is an open access article distributed in accordance with the Creative Commons Attribution Non Commercial (CC BY-NC 4.0) license, which permits others to distribute, remix, adapt, build upon this work non-commercially, and license their derivative works on different terms, provided the original work is properly cited, appropriate credit is given, any changes made indicated, and the use is non-commercial. See: http://creativecommons.org/licenses/by-nc/4.0/.

\section{REFERENCES}

1. Aryee A, Price N. Antimicrobial stewardship - can we afford to do without it? Br J Clin Pharmacol 2015;79:173-81.

2. Bell BG, Schellevis F, Stobberingh E, et al. A systematic review and meta-analysis of the effects of antibiotic consumption on antibiotic resistance. BMC Infect Dis 2014;14:1-25.

3. Power RF, Linnane B, Martin R, et al. The first reported case of Burkholderia contaminans in patients with cystic fibrosis in
Ireland: from the Sargasso Sea to Irish Children. BMC Pulm Med 2016;16:1-5.

4. O'Connor C, Cormican M, Boo TW, et al. An Irish outbreak of New Delhi metallo- $\beta$-lactamase (NDM)- 1 carbapenemase-producing Enterobacteriaceae: increasing but unrecognized prevalence. J Hosp Infect 2016;94:351-7.

5. O'Connor $\mathrm{C}, \mathrm{O}$ 'Connell $\mathrm{NH}$, Commane $\mathrm{M}$, et al. Limerick: forever associated with five lines of rhyme or infamous for irrepressible carbapenemase-producing Enterobacteriaceae for all time? J Hosp Infect 2016;93:155-6.

6. Health Products Regulatory Authority. Report on Antimicrobial Resistance Report. Dublin, 2016.

7. World Health Organisation (WHO). Antimicrobial resistance: global report on surveillance 2014 Report. Switzerland, 2014.

8. SARI Hospital Antimicrobial Stewardship Working Group. Guidelines for Antimicrobial Stewardship in Hospitals in Ireland. Dublin, Ireland, 2009:1-50.

9. Nathan C, Cars O. Antibiotic resistance-problems, progress, and prospects. N Engl J Med 2014;371:1761-3.

10. Harbarth $\mathrm{S}$, Balkhy $\mathrm{HH}$, Goossens $\mathrm{H}$, et al. Antimicrobial resistance: one world, one fight!. Antimicrob Resist Infect Control 2015;4:49.

11. The National Institute for Health and Care Excellence (NICE). Antimicrobial stewardship: systems and processes for effective antimicrobial medicine use. UK: NICE Guideline (NG 15), 2015.

12. The National Institute for Health and Care Excellence (NICE). Antimicrobial stewardship: changing risk related behaviours in the general population. UK: NICE Guideline (NG 63), 2017.

13. Harris AM, Hicks LA, Qaseem A, et al. Appropriate antibiotic use for acute respiratory tract infection in adults: advice for high-value care from the american college of physicians and the centers for disease control and prevention. Ann Intern Med 2016;164:425-34.

14. Lee ML, Cho CY, Hsu CL, et al. Recent trends in antibiotic prescriptions for acute respiratory tract infections in pediatric ambulatory care in Taiwan, 2000-2009: A nationwide populationbased study. J Microbiol Immunol Infect 2016;49:554-60.

15. The National Institute for Health and Care Excellence (NICE). Selflimiting respiratory tract infections -antibiotic prescribing. UK: NICE Clinical Guideline (CG 69), 2008.

16. Meropol SB, Localio AR, Metlay JP. Risks and benefits associated with antibiotic use for acute respiratory infections: a cohort study. Ann Fam Med 2013;11:165-72.

17. Fahey T, Stocks N, Thomas T. Systematic review of the treatment of upper respiratory tract infection. Arch Dis Child 1998;79:225-30.

18. Little P, Watson L, Morgan S, et al. Antibiotic prescribing and admissions with major suppurative complications of respiratory tract infections: a data linkage study. Br J Gen Pract 2002;52:187-90.

19. Butler CC, Hood K, Verheij T, et al. Variation in antibiotic prescribing and its impact on recovery in patients with acute cough in primary care: prospective study in 13 countries. BMJ 2009;338:b2242.

20. Gulliford MC, Moore MV, Little P, et al. Safety of reduced antibiotic prescribing for self limiting respiratory tract infections in primary care: cohort study using electronic health records. BMJ 2016;354:i3410.

21. Garbutt JM, Banister C, Spitznagel E, et al. Amoxicillin for acute rhinosinusitis: a randomized controlled trial. JAMA 2012;307:685-92.

22. The National Institute for Health and Care Excellence (NICE). Medicines Evidence Commentary: Acute cough - public expectation of symptom duration differs from published evidence. UK: The National Institute for Health and Care Excellence (NICE), 2013.

23. Spinks A, Glasziou PP, Del Mar CB. Antibiotics for sore throat. Cochrane Database Syst Rev 2013:Cd000023.

24. Little P, Gould C, Williamson I, et al. Reattendance and complications in a randomised trial of prescribing strategies for sore throat: the medicalising effect of prescribing antibiotics. BMJ 1997;315:350-2

25. Yaeger JP, Temte JL, Hanrahan LP, et al. Roles of clinician, patient, and community characteristics in the management of pediatric upper respiratory tract infections. Ann Fam Med 2015;13:529-36.

26. Silverman M, Povitz M, Sontrop JM, et al. Antibiotic prescribing for nonbacterial acute upper respiratory infections in elderly persons. Ann Intern Med 2017;166:765-74.

27. Schroeck JL, Ruh CA, Sellick JA, et al. Factors associated with antibiotic misuse in outpatient treatment for upper respiratory tract infections. Antimicrob Agents Chemother 2015;59:3848-52.

28. Teng CL. Antibiotic prescribing for upper respiratory tract infections in the Asia-Pacific region: a brief review. Malays Fam Physician 2014;9:18-25.

29. Murphy M, Bradley CP, Byrne S. Antibiotic prescribing in primary care, adherence to guidelines and unnecessary prescribing-an Irish perspective. BMC Fam Pract 2012;13:43.

30. Rún Sigurðardóttir N, Nielsen AB, Munck A, et al. Appropriateness of antibiotic prescribing for upper respiratory tract infections in general 
practice: Comparison between Denmark and Iceland. Scand J Prim Health Care 2015;33:269-74.

31. Davis ME, Liu TL, Taylor YJ, et al. Exploring patient awareness and perceptions of the appropriate use of antibiotics: a mixed-methods study. Antibiotics 2017:6:23

32. Watkins L, Sanchez G, Albert A, et al. Knowledge and attitudes regarding antibiotic use among adult consumers, adult hispanic consumers, and health care providers - United States, 2012-2013. Mmwr Usa 2015;64:767.

33. PublicHealth England. Health matters: antimicrobial resistance. UK: PH England, 2015.

34. McDonagh M, Peterson K, Winthrop K, et al. Improving antibiotic prescribing for uncomplicated acute respiratory tract infections. Rockville (MD): AHRQ WebM\&M, 2016.

35. Lindberg BH, Gjelstad S, Foshaug M, et al. Antibiotic prescribing for acute respiratory tract infections in Norwegian primary care out-ofhours service. Scand J Prim Health Care 2017;35:178-85.

36. Huibers L, Moth G, Christensen MB, et al. Antibiotic prescribing patterns in out-of-hours primary care: a population-based descriptive study. Scand J Prim Health Care 2014;32:200-7.

37. Dyrkorn R, Gjelstad S, Espnes KA, et al. Peer academic detailing on use of antibiotics in acute respiratory tract infections. A controlled study in an urban Norwegian out-of-hours service. Scand J Prim Health Care 2016;34:180-5.

38. Elshout G, Kool M, Van der Wouden JC, et al. Antibiotic prescription in febrile children: a cohort study during out-of-hours primary care. $J$ Am Board Fam Med 2012;25:810-8.

39. Giesen $\mathrm{P}$, Willekens $\mathrm{M}$, Mokkink $\mathrm{H}$, et al. Out-of-hours primary care: development of indicators for prescribing and referring. Int J Qual Health Care 2007;19:289-95.

40. Willekens M, Giesen P, Plat E, et al. Quality of after-hours primary care in The Netherlands: adherence to national guidelines. BMJ Qual Saf 2011;20:223-7.

41. Hayward GN, Fisher RF, Spence GT, et al. Increase in antibiotic prescriptions in out-of-hours primary care in contrast to in-hours primary care prescriptions: service evaluation in a population of 600000 patients. J Antimicrob Chemother 2016;71:2612-9.

42. Debets VE, Verheij TJ, van der Velden AW. SWAB's Working Group on Surveillance of Antimicrobial Use. Antibiotic prescribing during office hours and out-of-hours: a comparison of quality and quantity in primary care in the Netherlands. $\mathrm{Br} J$ Gen Pract 2017:67:e178-86.

43. Kallestrup P, Bro F. Parents' beliefs and expectations when presenting with a febrile child at an out-of-hours general practice clinic. Br J Gen Pract 2003;53:43-4.

44. Courtenay M, Rowbotham S, Lim R, et al. Antibiotics for acute respiratory tract infections: a mixed-methods study of patient experiences of non-medical prescriber management. BMJ Open 2017;7:e013515.

45. Fletcher-Lartey S, Yee M, Gaarslev C, et al. Why do general practitioners prescribe antibiotics for upper respiratory tract infections to meet patient expectations: a mixed methods study. BMJ Open 2016;6:e012244.

46. Md Rezal RS, Hassali MA, Alrasheedy AA, et al. Physicians' knowledge, perceptions and behaviour towards antibiotic prescribing: a systematic review of the literature. Expert Rev Anti Infect Ther 2015;13:665-80.

47. Wong CK, Liu Z, Butler CC, et al. Help-seeking and antibiotic prescribing for acute cough in a Chinese primary care population: a prospective multicentre observational study. NPJ Prim Care Respir Med 2016;26:15080.

48. Gambarelli L, Montanari C, Manni A, et al. Antibiotics in viral upper respiratory tract infections. Ricerca e Pratica 2002;18:152-6.

49. Biezen R, Brijnath B, Grando D, et al. Management of respiratory tract infections in young children-A qualitative study of primary care providers' perspectives. NPJ Prim Care Respir Med 2017;27:15.

50. Hamm RM, Hicks RJ, Bemben DA. Antibiotics and respiratory infections: are patients more satisfied when expectations are met? $J$ Fam Pract 1996;43:56-62.

51. Shlomo V, Adi R, Eliezer K. The knowledge and expectations of parents about the role of antibiotic treatment in upper respiratory tract infection-a survey among parents attending the primary physician with their sick child. BMC Fam Pract 2003;4:20.

52. Martin CL, Njike VY, Katz DL. Back-up antibiotic prescriptions could reduce unnecessary antibiotic use in rhinosinusitis. J Clin Epidemiol 2004;57:429-34.
53. Soma M, Slapgård H, Lerberg M, et al. [Patients' expectations of antibiotics for acute respiratory tract infections]. Tidsskr Nor Laegeforen 2005;125:1994-7.

54. Ong S, Nakase J, Moran GJ, et al. Antibiotic use for emergency department patients with upper respiratory infections: prescribing practices, patient expectations, and patient satisfaction. Ann Emerg Med 2007:50:213-20.

55. Ackerman SL, Gonzales R, Stahl MS, et al. One size does not fit all: evaluating an intervention to reduce antibiotic prescribing for acute bronchitis. BMC Health Serv Res 2013;13:462.

56. Hardy-Holbrook R, Aristidi S, Chandnani V, et al. Antibiotic resistance and prescribing in Australia: current attitudes and practice of GPs. Healthc Infect 2013;18:147-51.

57. McNulty CA, Nichols T, French DP, et al. Expectations for consultations and antibiotics for respiratory tract infection in primary care: the RTI clinical iceberg. Br J Gen Pract 2013;63:e429-36.

58. Dempsey PP, Businger AC, Whaley LE, et al. Primary care clinicians' perceptions about antibiotic prescribing for acute bronchitis: a qualitative study. BMC Fam Pract 2014;15:194

59. McKay R, Mah A, Law MR, et al. Systematic review of factors associated with antibiotic prescribing for respiratory tract infections. Antimicrob Agents Chemother 2016;60:4106-18.

60. Welschen I, Kuyvenhoven M, Hoes A, et al. Antibiotics for acute respiratory tract symptoms: patients' expectations, GPs' management and patient satisfaction. Fam Pract 2004;21:234-7.

61. Altiner A, Knauf A, Moebes J, et al. Acute cough: a qualitative analysis of how GPs manage the consultation when patients explicitly or implicitly expect antibiotic prescriptions. Fam Pract 2004:21:500-6.

62. Linder JA, Singer DE. Desire for antibiotics and antibiotic prescribing for adults with upper respiratory tract infections. J Gen Intern Med 2003;18:795-801.

63. Kautz-Freimuth $\mathrm{S}$, Redaèlli $\mathrm{M}$, Samel $\mathrm{C}$, et al. Parental views on acute otitis media (AOM) and its therapy in children-results of an exploratory survey in German childcare facilities. BMC Pediatr 2015;15:199.

64. Department of Health Ireland. Health Service Executive. Cards and schemes: Medical cards:Dublin. 2018 https://www.hse.ie/eng/cardsschemes/medical-card/ (Accessed 07 Feb 2018).

65. Panagakou SG, Spyridis N, Papaevangelou V, et al. Antibiotic use for upper respiratory tract infections in children: a cross-sectional survey of knowledge, attitudes, and practices (KAP) of parents in Greece. BMC Pediatr 2011;11:60.

66. Ashworth $\mathrm{M}$, White $\mathrm{P}$, Jongsma $\mathrm{H}$, et al. Antibiotic prescribing and patient satisfaction in primary care in England: cross-sectional analysis of national patient survey data and prescribing data. $\mathrm{Br} \mathrm{J}$ Gen Pract 2016;66:e40-6.

67. Murphy M, Byrne S, Bradley CP. Influence of patient payment on antibiotic prescribing in Irish general practice: a cohort study. $\mathrm{Br} J$ Gen Pract 2011;61:e549-55.

68. Ab Rahman N, Teng CL, Sivasampu S. Antibiotic prescribing in public and private practice: a cross-sectional study in primary care clinics in Malaysia. BMC Infect Dis 2016;16:208

69. Kumar S, Little P, Britten N. Why do general practitioners prescribe antibiotics for sore throat? Grounded theory interview study. BMJ 2003;326:138.

70. Vaz LE, Kleinman KP, Lakoma MD, et al. Prevalence of parental misconceptions about antibiotic use. Pediatrics 2015;136:221-31.

71. Rousounidis A, Papaevangelou V, Hadjipanayis A, et al. Descriptive study on parents' knowledge, attitudes and practices on antibiotic use and misuse in children with upper respiratory tract infections in Cyprus. Int J Environ Res Public Health 2011;8:3246-62.

72. Salazar ML, English TM, Eiland LS. Caregivers' baseline understanding and expectations of antibiotic use for their children. Clin Pediatr 2012;51:632-7.

73. Little P, Stuart B, Francis N, et al. Effects of internet-based training on antibiotic prescribing rates for acute respiratory-tract infections: a multinational, cluster, randomised, factorial, controlled trial. Lancet 2013:382:1175-82.

74. Chaintarli K, Ingle SM, Bhattacharya A, et al. Impact of a United Kingdom-wide campaign to tackle antimicrobial resistance on self-reported knowledge and behaviour change. BMC Public Health 2016;16:393.

75. Stanton N, Francis NA, Butler CC. Reducing uncertainty in managing respiratory tract infections in primary care. $\mathrm{Br} J$ Gen Pract 2010;60:e466-75. 